\title{
Temporal order identification for tone/noise stimuli with onset transitions
}

\author{
RICHARD E. PASTORE, JODY KAPLAN LAYER, CRYSTLE B. MORRIS, \\ and ROBERT J. LOGAN \\ State University of New York University Center, Binghamton, New York
}

\begin{abstract}
Temporal order of onset identification boundaries and difference thresholds (DLg) were measured for stimuli modeled after two formant spech stimuli that varied in voice onset time (VOT). The stimuli had dynamic onset transitions and consisted of a tone pair that varied in onset relative to a noise whose center frequency matched the higher frequency tone. DLs were measured relative to 0 - and 7-msec onset delays (as well as 49- and 56-msec onset delays) by using a method of constant stimuli with a two-interval temporal forced choice psychophysical procedure. Discrete thresholds were found for noise lead conditions, but tone lead conditions were very difficult for most subjects. With rising-onset stimuli, evidence was found for long DLs based upon a fixed threshold location at 32-38 msec, and thus independent of the standard stimulus. With fallingonset stimuli, the short (5- to 20 -msec) DLs were roughly proportional to the standard (0- or 7 . msec) onset difference, although there was evidence for an additional fixed perceptual boundary at a longer (30- to 40-msec) onset difference. A noise burst at stimulus onset seemed to act as a type of masking stimulus, causing a shift in temporal order threshold to longer onset differences. The 30- to 40-msec fixed threshold location is similar in magnitude to those typical of VOT voicing boundaries for stop consonants of English.
\end{abstract}

Speech signals are a form of acoustic stimuli that provide the link between the production and perception of speech categories. Logically, there should be characteristics in speech stimuli that are direct functions of the production of speech categories and that serve to cue the perception of those categories. These characteristics must be effective cues for perception in the context of the high degree of variability found in speech signals across the many different conditions for normal listening. Speech researchers have long sought to identify the nature of such invariant characteristics of speech signals. While many researchers have become convinced that the correspondence between categories of production and perception is based upon a special set of processes or modes of processing (e.g., Liberman \& Mattingly, 1985), we believe that the failure to identify invariant cues may stem from a focus on low-level acoustic differences in simple stimuli. Our research attempts to identify invariant cues for one class of initial position consonants by providing a psychophysical mapping of acoustic stimuli that are similar in their spectral and temporal patterns to that class of speech stimuli.

One type of simple invariant cue hypothesis is that there exist natural, stable discontinuities in the perception of acoustic stimuli, with speech categories having developed

This material is based upon work supported in part by the National Science Foundation Grants 83028373 and 8608643 . Any opinions, findings, and conclusions or recommendations expressed in this article are those of the authors and do not necessarily reflect the views of the National Science Foundation. The authors' mailing address is Department of Psychology, SUNY, Binghamton, NY 13901. to take advantage of these natural discontinuities. An example of this simple cue hypothesis is the conjecture that the threshold for identifying the temporal order of onset of stimulus components (TOJ) serves as a cue for the perception of voicing contrasts (Hirsh, 1959; Pastore, Harris, \& Kaplan, 1982; Pisoni, 1977). We examined in detail research based upon this TOJ hypothesis with simple stimuli and research mapping the voicing boundary for synthetic CV syllables. We agree with Summerfield (1982) that the TOJ hypothesis, in its simplest, most general form, does not provide a reasonable basis for explaining the perception of voicing categories.

More recent attempts to identify invariant cues for speech categories have tended to look beyond simple acoustic attributes, and to focus on more spectrally complex stimulus characteristics distributed in time (e.g., short-term onset spectra for place perception; Blumstein \& Stevens, 1981). In the present research, we investigated TOJ for spectrally complex, time-varying stimuli. The use of relatively complex stimuli in psychophysical tasks should allow for a wider variety of perceptual interactions than are found with the use of simple tones, and thus may be more likely to exhibit the types of natural qualitative changes in perception that may have fostered the development of speech categories.

Although the ultimate goal of the present research was to identify the stimulus characteristics that cue the perception of voicing contrasts in speech stimuli, the immediate goal was to provide a specification and understanding of TOJ for stimuli that are more complex in spectral and temporal characteristics than the tones employed in previous TOJ research, yet are simple relative to speech 
stimuli. Careful investigation of TOJ adds to our understanding of the manner in which human sensory and perceptual systems process this specific class of stimulus properties. We also assume that this understanding will help provide a specification of a relatively peripheral level of stimulus processing that represents the input stage to the higher order processing of complex stimuli, including speech.

Hirsh (1959) provided the first extensive mapping of TOJ for pairs of stationary tones (TOT) and for the pairing of a tone and a noise burst. He found TOJ to be constant at approximately $17 \mathrm{msec}$. For stimuli with brief rise times (7 msec or less), TOJ generally was found to be independent of the frequency of the tones (or tone/noise stimuli) as well as the relative intensity of the stimuli (20 phon range). ${ }^{2}$ This $17-$ msec TOJ threshold was cited as being similar to the approximately 20 -msec voice onset time (VOT) boundary between voiced and voiceless categories for English stop consonants in syllable initial position (J. D. Miller, Wier, Pastore, Kelly, \& Dooling, 1976; Pisoni, 1977). Later research demonstrated that the category boundary for labial stop consonants was located at 24 to $26 \mathrm{msec}$, rather than at $20 \mathrm{msec}$ (see below). A difference of $8 \mathrm{msec}$ in onset threshold or boundary for TOT (17 msec) and VOT $(25 \mathrm{msec})$ is probably both statistically and behaviorally significant. Typically, boundaries for alveolar and velar English stop consonants are at even longer VOT onset differences (see below), and thus are even more dissimilar to TOJ for simple stimuli.

The nature of TOJ for tones also may be a problem for this simple acoustic hypothesis. Rosen and Howell (1987) suggested that only a qualitative change in perception, which would represent a sharp, natural boundary, could serve as a basis for categorical perception of voicing contrasts. They noted that Hirsh had found a gradual change in identification performance that was symmetric around chance performance at onset synchrony. The 17-msec estimate for TOJ represents a statistically defined threshold, rather than the location of an abrupt qualitative change in perception. Figure 2 (below) shows the type of psychometric function that, according to Rosen and Howell, should be found if TOJ represents a qualitative change in perception. However, in view of Pisoni's (1977) finding that categorical perception for TOT has a boundary location between approximately 15 and $20 \mathrm{msec}$, TOJ must represent some form of perceptual marker or anchor.

Recent research has delineated the effects of changes in voicing boundary location for syllable initial stop consonants as a function of major stimulus parameters or cues. This research establishes a set of standards by which to evaluate our revised TOJ hypothesis. We are restricting our summary to stop consonants of English in syllable initial position, noting that nominally equivalent consonants in other syllable or word positions, and in other languages, may not necessarily be equivalent in acoustic, phonetic, or phonological terms (Keating, 1984).
Research with synthetic speech stimuli (summarized in Table 1) has demonstrated that the voicing contrast boundaries for VOT are a function of a number of stimulus parameters. Table 1 also provides an indication of the range of voicing boundary locations, and the changes in those locations as a function of various speech stimulus parameters or cues. The voicing boundary for labial stop consonants is quite stable across studies, averaging approximately $25 \mathrm{msec}$. Although the change in VOT boundary is sometimes quite small (see Table 1), the voicing boundaries for stimuli with velar and alveolar places of articulation are typically at longer VOT locations, when place of articulation cues are varied.

While Darwin and Pearson (1982) suggested that voicing onset might be cued by overall intensity, other researchers have focused on the relative intensity of aspiration noise. Liberman, Delattre, and Cooper (1958) reported that the presence of aspiration noise prior to voicing onset improves the perception of voicelessness relative to first formant cutback alone, although the substitution of noise for the transitions to all three formants failed to produce the perception of voicelessness. Repp (1979) found that increasing the intensity of the aspiration noise component relative to the voiced portion of the stimulus decreased the VOT voicing boundary. Darwin and Seton (1983), using a wide range of relative aspiration noise intensities, replicated Repp's finding that the voicing boundary changes at a rate of approximately $0.43 \mathrm{msec} / \mathrm{dB}$ change in aspiration noise.

Voicing boundary is directly proportional to the first (F1) formant frequency and transition duration, and inversely proportional to $F 1$ transition onset frequency, but is not altered by changes in these same aspects of F2. In addition, VOT voicing boundary was found to be a direct function of the duration of the vowel, although these duration effects usually represent small changes in boundary location that may not be perceptually significant (Jongman, 1986). The summary of parameter influences on voicing boundary in Table 1 is extensive; however, it ignores research on stress, rate, and other parameters that are important to speech, but that are well beyond the scope of the present research.

Recent investigations of TOJ (summarized in Table 2) have attempted to map parameter dependencies similar to those summarized in Table 1, but for nonspeech stimuli ranging in complexity from stationary tones to tones with onset transitions. ${ }^{3}$ Although Pastore, Harris, and Kaplan (1982) found significant increases in TOJ resulting from increased stimulus duration and stimulus rise time, TOJ for tones is otherwise independent of all stimulus parameters investigated to date, including relative amplitude and the frequency of $f 1$. In addition, for nearly all simple stimulus (TOT and NOT) conditions, TOJ is located at onset asynchronies considerably shorter than typical VOT voicing boundaries. If TOJ is the basis for the perception of voicing contrasts, we would therefore have 
Table 1

Synthetic Speech Voicing (VOT) Boundaries for Syllable Initial English Stop Consonants

PLACE OF ARTICULATION (Cued by burst and F2 transition)

\begin{tabular}{lcc} 
Labial & Apical/Alveolar & Velar \\
\hline 25 & 35 & $42 \mathrm{msec}$ \\
24.6 & 27.8 & $28.3 \mathrm{msec}$ \\
24.2 & & $35.8 \mathrm{msec}$ \\
24 & 22 &
\end{tabular}

Lisker \& Abramson, 1970

J. L. Miller, 1977

Soli, 1983

Massaro \& Oden, 1980

RELATIVE ASPIRATION INTENSITY

\begin{tabular}{|c|c|c|c|}
\hline Asp. Ampl.: & -6 & 0 & $+6 \mathrm{~dB}$ \\
\hline VOT: & 31.8 & 28.1 & $27.3 \mathrm{msec}$ \\
\hline
\end{tabular}

$0.43 \mathrm{msec} / \mathrm{dB}$ for broad range of conditions

VOWEL F1 FREQUENCY

$\begin{array}{lllll}\text { F1: } & 200 & 300 & 400 & 500 \mathrm{~Hz} \\ \text { Exp. 1: } & 49.5 & 41.1 & 31.9 & 29.9 \\ \text { Exp. 2: } & 40.0 & 36.4 & 29.5 & 28.1\end{array}$

VOWEL F2 FREQUENCY

No VOT dependency

FI TRANSITION DURATION

$\begin{array}{lllllr} & 25 & 55 & 70 & 85 & 100 \mathrm{msec} \\ \begin{array}{l}\text { /da-ta/ } \\ \text { /da-ta/ }\end{array} & 21 & 32 & 41 & 39 & \begin{array}{r}47 \mathrm{msec} \\ \mathrm{msec}\end{array}\end{array}$

F2 TRANSITION DURATION

Very little effect on VOT

F1 ONSET FREQUENCY

Higher frequency $=$ Shorter VOT

VOWEL DURATION

\begin{tabular}{lccc} 
& Short & Long & Diff. \\
\cline { 2 - 4 } /bi-pi/ & 28.1 & 29.5 & $1.4 \mathrm{msec}$ \\
/bis-pis/ & 23.5 & 26.4 & $2.9 \mathrm{msec}$ \\
/biz-piz/ & 22.8 & 26.5 & $3.7 \mathrm{msec}$ \\
/bi-pi/ (natural tokens) & & $1.9 \mathrm{msec}$ \\
& & & \\
& 210 & $431 \mathrm{msec}$ & Diff. \\
/beace-peace/ & 20 & 27 & $7 \mathrm{msec}$ \\
/beef-peef/ & 27 & 32 & $5 \mathrm{msec}$
\end{tabular}

Repp, 1979

Darwin \& Seton, 1983

Summerfield, 1982

Summerfield, 1982

Summerfield \& Haggard, 1977

Lisker et al., 1977

J. L. Miller \& Eimas, 1981 (Cited in Summerfield, 1981)

Lisker et al., 1977

Stevens \& Klatt, 1974

Lisker, 1975

Lisker et al., 1977

Summerfield \& Haggard, 1977

Summerfield, 1981

Summerfield, 1981

Summerfield, 1981

Jongman, 1986

J. L. Miller, 1986

J. L. Miller, 1986 to account for a shift from the approximate 10- to 24-msec range of values for syllable length TOT stimuli to the 20to $50-\mathrm{msec}$ range of voicing boundaries summarized in Table 1.

The problem of very short threshold locations also is found with onset identification tasks for the pairing of a noise burst with a tone (Hirsh, 1959) and with a filtered buzz (J. D. Miller et al., 1976; Summerfield, 1982). Very brief thresholds thus seem to be a general characteristic of onset perception for simple stimuli. However, Pastore et al. (1982) reported that, for the same subjects and stimuli, TOT labeling boundaries were consistently longer than TOJ locations (see Table 2), although still shorter than typical voicing boundary locations. Thus, the difference between brief TOJ locations and longer VOT voicing boundary locations, although clearly not equivalent, may have been enhanced by methodological differences.

Hillenbrand (1984) investigated TOJ for tonal stimuli with initial FM transitions to F1 and F2 that, while clearly not speech, better approximated the dynamic onset characteristics of consonant-vowel (CV) syllables. Using a stimulus continuum created by substituting silence for the initial portion of the $f 1$ component (thus also varying the onset frequency of the transition), Hillenbrand found somewhat longer thresholds. He also found that TOJ for such stimuli was a direct function of the duration of the 
Table 2

Temporal Order of Onset (TOJ) for Nonspeech Stimuli

\begin{tabular}{|c|c|c|c|c|}
\hline \multicolumn{5}{|l|}{ TONE PAIRS (TOT): } \\
\hline \multicolumn{5}{|l|}{ Relative Amplitude: } \\
\hline \multicolumn{5}{|c|}{$\begin{array}{l}\text { No effect: } \pm 20 \text { Phon (Rise time }>7 \mathrm{msec} \text { ) } \\
\text { No effect: } \pm 12 \mathrm{~dB}\end{array}$} \\
\hline \multicolumn{5}{|l|}{ Frequency: } \\
\hline [17-24 msec (in & penden & freq. & \& lead/ & \\
\hline Low Freq.: & 200 & 300 & 400 & $500 \mathrm{~Hz}$ \\
\hline $\begin{array}{l}\text { Exp. 1: } \\
\text { Exp. 2: }\end{array}$ & $\begin{array}{l}20.6 \\
21.4\end{array}$ & $\begin{array}{l}14.1 \\
23.4\end{array}$ & $\begin{array}{l}13.3 \\
18.8\end{array}$ & $\begin{array}{l}11.7 \\
22.4\end{array}$ \\
\hline
\end{tabular}

Stimulus Duration:

\begin{tabular}{lcrcc} 
Duration: & 10 & 30 & 100 & $300 \mathrm{msec}$ \\
\cline { 2 - 5 } Threshold: & 4.7 & 9.4 & 10.0 & 12.2 \\
Labeling: & 7.2 & 12.8 & 13.9 & 18.9
\end{tabular}

Rise Time:

\begin{tabular}{lcccc} 
Rise Time: & 10 & 30 & 50 & $100 \mathrm{msec}$ \\
\cline { 2 - 5 } 100-msec Dur.: 9.1 & 10.9 & 13.3 & $18.2 \mathrm{msec}$ \\
300-msec Dur.: 12.1 & 13.9 & 17.9 & $23.6 \mathrm{msec}$
\end{tabular}

TONE/NOISE BURST:

17-24 msec independent of lead/lag

NOISE-BUZZ STIMULI:

General:

Categorical Perception: $15.1 \mathrm{msec}$

F1 Frequency:

\begin{tabular}{lcccc} 
Frequency: & 200 & 300 & 400 & $500 \mathrm{~Hz}$ \\
\cline { 2 - 5 } Exp. 1: & 27.2 & 20.0 & 16.9 & $19.2 \mathrm{msec}$ \\
Exp. 2: & 21.1 & 20.9 & 20.6 & $19.9 \mathrm{msec}$
\end{tabular}

TONES WITH INITIAL TRANSITIONS:

F1 Transition Duration:

Duration:

TOT:

\begin{tabular}{lll}
25 & 50 & $75 \mathrm{msec}$ \\
\hline 18 & 24 & $29 \mathrm{msec}$
\end{tabular}

F1 Frequency:

Frequency:

Discrim.:

Labeling:

\begin{tabular}{ccc}
250 & 450 & $750 \mathrm{~Hz}$ \\
\hline 26 & 18 & $22 \mathrm{msec}$ \\
26 & 21 & $25 \mathrm{msec}$
\end{tabular}

Hirsh, 1959

Pisoni, 1977

Hirsh, 1959

Summerfield, 1982

Summerfield, 1982

Pastore et al., 1982

Pastore et al., 1982

Pastore et al., 1982

Pastore et al., 1982

Hirsh, 1959

J. D. Miller et al., 1976

Summerfield, 1982

Summerfield, 1982

Hillenbrand, 1984

Hillenbrand, 1984

Hillenbrand, 1984 lower frequency transition, but he failed to find the type of systematic dependency on $f 1$ frequency reported for such voicing continua. While the addition of initial frequency transitions increased the absolute TOJ boundary location, it did not have the expected dependency of threshold or boundary on specific stimulus parameters.

This review supports the conclusion that TOJ for stationary tonal stimuli is located at too brief an onset difference, and that, in the context of changes in simple stimulus properties, is too stable to support the hypothesis that this threshold is a basis for the voicing boundary for speech. However, TOJ for time-varying tonal stimuli is located at somewhat longer onset differences. It is quite possible that additional increases in the complexity of the stimuli will further increase the location of the order identification threshold, which, in turn, will result in that threshold's greater dependency on various aspects of the stimulus. If TOJ location (and the dependency of that location on stimulus parameters) is similar to that found for the voicing boundary in speech, then we must again seriously consider TOJ to be a possible basis for the perception of voicing differences.

We began our current investigation with a more detailed comparison of the physical stimuli typically employed in studies of the voicing contrast and in studies of TOJ. In stop consonants, an initial release burst is followed by 
stimulation of higher vocal tract resonances (F2, F3, .., but not F1) with relatively high frequency aspiration noise; in other languages, the aspiration noise may be absent or perceptually unimportant. Then, beginning at voicing onset, there is stimulation of F1 and the higher vocal tract resonances by the harmonically rich glottal source. The release burst is quite prominent in most natural, syllableinitial, velar, and alveolar stop consonants, although the release burst in natural labial stops may be very weak or absent (Zue, 1976). A prominent release burst is included in synthetic stimuli that are employed in nearly all recent studies of voicing. Natural speech stimuli, and their synthetic counterparts, are temporally and spectrally complex relative to the acoustic stimuli employed in TOJ studies.

If TOJ plays a significant role in the perception of voicing differences in English stop consonants, then the acoustic basis of that temporal order limitation might involve the recognition or identification of aspiration noise onset prior to voicing onset. In addition, the release burst may serve as a masking stimulus for the detection or recognition of critical stimulus onset characteristics. The first experiment was designed to investigate the role of highfrequency, band-limited noise on the perception of temporal order of onset. The remaining experiments were designed to investigate the influence of an initial burst of noise on temporal order perception, and to investigate specific stimulus and methodological issues raised in the first experiment.

\section{GENERAL METHODS}

\section{Subjects}

Four SUNY-Binghamton undergraduates served as subjects in each of the experiments. All reported normal hearing. Of the 4 used in Experiments 1 and 2, Subjects 1 and 3 had worked as professional subjects in our laboratory for at least 1 year; Subjects 2 and 4 were naive when they took part in Experiment 1, which immediately preceded Experiment 2 . Subjects 1 and 4 were male, and Subjects 2 and 3 were female. Four new subjects (Subjects 5 to 8 ) were used in Experiments 3 and 4. All were females, and all were naive to psychophysical tasks when they began Experiment 3, which immediately preceded Experiment 4.

\section{Stimuli}

Identical sets of stimuli were employed in all experiments; they are summarized in Figure 1. All stimuli were digitized (12-bit, 10$\mathrm{kHz}$ sample rate, $4-\mathrm{kHz}$ lowpass filter). The basic stimuli were produced by mixing a noise component (Figure 1, upper panels) and a complex tonal component (Figure 1, lower panels), with temporal order of onset defined in terms of the onset of the noise relative to the onset of the pair of tonal components. The two basic types of stimuli differ in terms of the nature of the onset to the higher frequency component. The frequency parameters of these rising and falling $f 2$ onset stimuli (Figure 1, upper and lower pairs of panels) were based roughly on synthetic labial and velar stimuli used in published studies of voicing contrasts. Our stimuli had frequency and amplitude (linear voltage change) transitions over the first $56 \mathrm{msec}$, and a 10-msec amplitude offset ramp. The amplitude onset and offset transitions were produced by multiplying the digital samples by a fractional gain weighting, with the weighting updated every 10 samples $(1 \mathrm{msec})$.
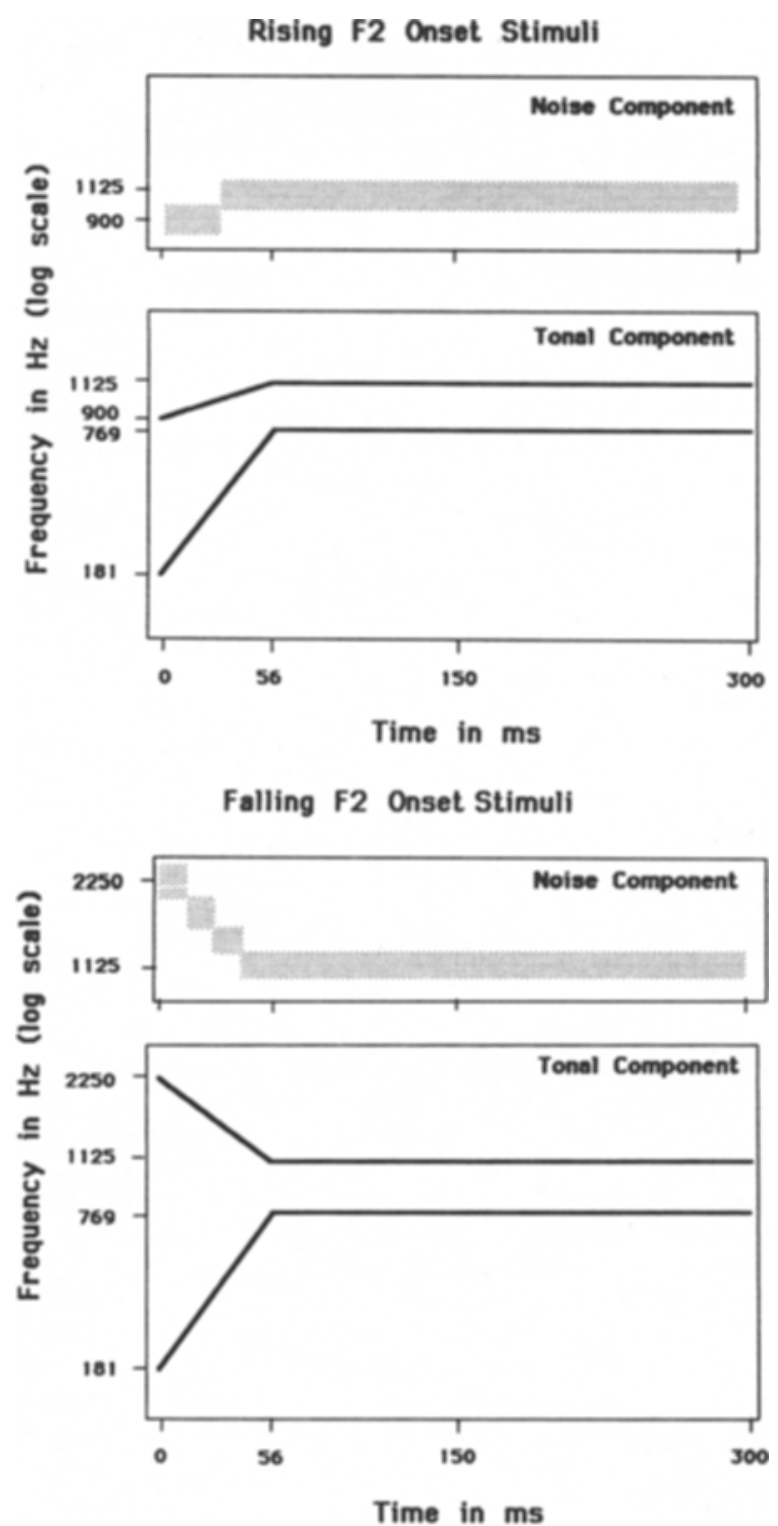

Figure 1. Stimuli employed in all four experiments. The stimuli consisted of two types of components. The tone component, in turn, had two components, with onset frequency and amplitude transitions over the initial $56 \mathrm{msec}$. The noise component roughly followed the frequency of the higher $(f 2)$ tone in the tone component. Stimuli differed in terms of the relative onset times of the tone and noise components. Stimuli were either short (150 msec) or long (300 msec), and had either a rising- or falling-onset to the $f 2$ transition.

The noise components were third-octave bands ( $48 \mathrm{~dB} /$ octave) of white noise that were joined at waveform zero crossings with common slope direction. After the initial rising- or falling-onset transitions, the noise components continued with a center frequency of $1125 \mathrm{~Hz}$ for the duration of the stimulus.

The digital representations of the tonal stimuli were computed by a software program that used the full 12-bit representation of the stimuli and updated the amplitude and frequency characteristic every 10 samples ( $1 \mathrm{msec}$ ). The falling and rising stimuli had a common $f 1$ component and different high-frequency transitions to a com- 
mon, steady-state $f 2$. The $f 2$ tone was set at a level $3.52 \mathrm{~dB}$ less than the $f 1$ tone. Except in Experiment 3, in which the intensity of the noise was varied, the noise component always was $71.5 \mathrm{~dB}(\mathrm{~A})$, and the analog tonal component was always $77.8 \mathrm{~dB}(\mathrm{~A})$.

Many VOT and TOT studies employed maximum temporal onset differences and transition durations of 50 to $60 \mathrm{msec}$, often with 10 - or 20 -msec step sizes. Based upon our experience with psychophysically experienced subjects, we decided to employ a 7-msec step size with a maximum onset difference and transition duration of $56 \mathrm{msec}$. Temporal onset differences were created by substituting silence (ground) for the first $n \operatorname{msec}(n=0,7,14,21,28$, $35,42,49,56$ ) of the delayed component, then applying a linear voltage-amplitude rise to the next $10 \mathrm{msec}$ of the delayed component. For example, a noise lead of $21 \mathrm{msec}$ was created by applying a zero-amplitude weighting to the first $21 \mathrm{msec}$ of the tone component and an amplitude weighting that grew linearly from 0 to 1.0 over the next $10 \mathrm{msec}$. The tone component thus grew in amplitude for 10 msec following onset until it matched the amplitude of the original tone component. The $10 \mathrm{msec}$ amplitude onset transitions eliminated any possible clicks that might have been created by the stimulus cutback procedure.

For each stimulus, there was a long $(300 \mathrm{msec})$ and a short (150 msec) version, which differed only in terms of the duration of the final steady-state portion of the stimuli. The noise and tonal components were separately synthesized, lowpass filtered, and attenuated, then mixed and presented diotically to the subjects. The noise and tonal components always had simultaneous offsets to eliminate the possibility that subjects might be able to use any duration or offset characteristics to perform the task.

\section{Stimulus and Procedural Considerations}

At various times during each experiment, subjects were asked to describe the nature of the stimuli being employed. The subjects used a wide variety of labels, including "weird tones," "bird calls," "duck quacks," and "dog barks." No subject ever described any of the stimuli as being similar to human speech. The subjects were never specifically asked whether the stimuli sounded like speech, because the suggestion that the stimuli might be perceived as speech could have invited concern that some form of speech perception mode might have been invoked.

At the end of each block of trials, the subjects were allowed to review the printed summary of the data they had just generated. This was the only feedback given to the subjects. Our goal was to encourage subjects to optimize their performance without focusing their attention on specific aspects of the stimuli.

\section{EXPERIMENT 1 ABSOLUTE TOJ THRESHOLDS}

In Experiment 1, we employed the method of constant stimuli to determine "absolute" TOJ values for our stimuli. In each trial, the subjects were required to indicate whether the tone or the noise component had an earlier onset. While the noise-lead stimuli were analogous to English stop-consonant stimuli that vary in VOT, the delayed noise condition (tone lead) did not correspond to consonants with voicing lead; where found, voicing lead is the consequence of voiced (nearly sinusoidal) stimulation of vocal tract resonances prior to the release of the consonant, which, in turn, corresponds to the onset of the formant transitions. Acoustically, this prereleased speech component is composed of only the lowest two or three harmonics of the fundamental frequency. For the psychophysical task in Experiment 1, it was important that there be an equal probability of the two possible response con- ditions (tone lead and noise lead), and that the subject not have been able to perform the task correctly by reporting the detection of an analogue to initial voice bar or any other stimulus characteristic irrelevant to temporal order of onset.

\section{Method}

The procedure for the first experiment was equivalent to the procedure employed by Hirsh (1959). The subjects were presented with single stimuli drawn randomly from the full stimulus continuum ( $-56-$ to $+56-\mathrm{msec}$ noise onset lead), and were instructed to push one of two buttons to indicate whether the tone or noise component had the earlier onset. On each trial, the subjects were instructed to respond, even if they were unsure and thus forced to guess. A block of trials consisted of a random ordering of five presentations of each of the stimuli from the given continuum (e.g., long rising stimuli), with $3.5 \mathrm{sec}$ between stimuli.

The subjects responded to two different random sequences of the four stimulus continua: long and short versions of falling- and risingonset stimuli (see General Methods), with a several-minute break between sequences. This procedure was repeated across $2-\mathrm{h}$ sessions until each subject had completed 20-45 trials for each stimulus; subject absences and the partial overlapping of subject running times caused differences in the actual number of trials per subject, and in the order in which sequences of the various conditions were run for the second, third, or fourth time.

\section{Results and Discussion}

Rosen and Howell (1987) suggested that if TOJ is a basis for voicing perception, there should be evidence for discrete, qualitative changes in perception for both tone leading and tone lagging the noise component. Such discrete, qualitative changes in perception should produce the type of psychometric function plotted in Figure 2. This predicted psychometric function is based upon the empirically measured 17 -msec absolute threshold for onset identification reported by Hirsh (1959), although longer thresholds would represent a more reasonable basis for the development of speech categories. According to this absolute-threshold hypothesis, the percent tone-lead response should be extremely high for supraliminal tonelead stimuli (negative noise lead times from approximately $-17 \mathrm{msec}$ to the maximum $-56-\mathrm{msec}$ stimulus em-

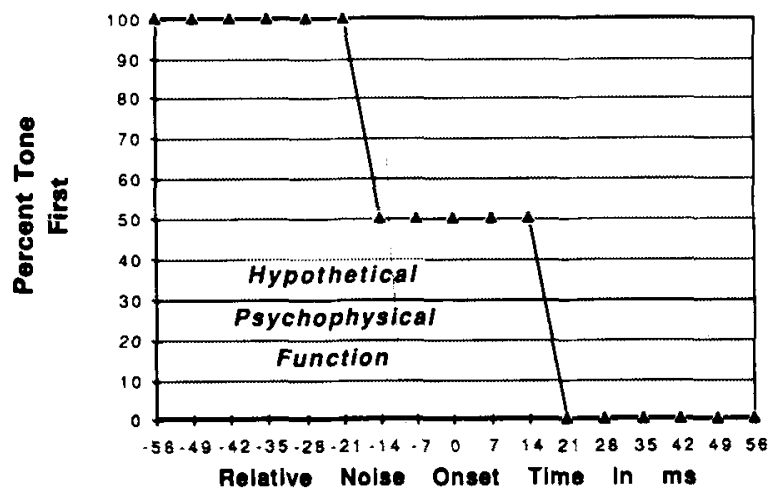

Figure 2. This figure shows a hypothetical psychophysical function for Experiment 1. The hypothetical function assumed that discrete perceptual changes occur at about -17 - and $+17-$ msec relative onset times. 
ployed). Likewise, this measure should be extremely low for supraliminal noise-lead stimuli (approximately $+17 \mathrm{msec}$ to the maximum $+56 \mathrm{msec}$ stimulus employed). The tone-lead response should be at chance (50\%) for the intermediate, subliminal stimuli. This theoretical psychometric function, with a central region of chance performance between two sharp, natural perceptual boundaries, has not been found in previous TOJ studies (see Rosen \& Howell, 1987), but would be expected if we were measuring symmetric, qualitative changes in perception along the physical onset continuum.

The discrimination functions for the 4 subjects are plotted in Figure 3. With several possible exceptions (long rising-onset stimuli for Subject 2; both rising-onset stimuli for Subject 3), the discrimination functions exhibited only TOJ for noise lead, and thus were not symmetric, as diagramed in Figure 2. Thus, while Hirsh (1959) found that TOJ did not appear to depend upon which stimulus components had the earlier onset, TOJ for our stimuli and the simple stimuli used by Pisoni (1977) did depend upon the ordering of the stimulus components.

With the falling-onset stimuli, this single threshold was at short onset differences which corresponded to the 10to 20-msec TOJ values typically reported. With the risingonset stimuli, the single threshold was located at onset asynchronies longer than any TOJ for previously studied nonspeech stimuli. These thresholds were located at onsets in the range of voicing boundaries typical of initialposition English stop consonants in general, although they were somewhat longer than the voicing boundaries typically found for synthetic labial VOT continua (Table 1). It is possible that this correspondence in onset boundary was entirely coincidental. It also is possible that our risingonset stimuli with dynamic tone/noise onset characteristics (unlike our falling-onset stimuli and the simple tone stimuli previously employed in TOT tasks) possessed at least one property critical to the perception of the voicing contrast at VOT boundaries typical of English stops. Finally, it is possible that the measure of TOJ was longer because of response bias rather than because of a perceptual limitation.

The asymmetric psychometric functions might have been due to very strong tone-lead response biases for all subjects, who thus would have exhibited only one of two existing thresholds. The three psychometric functions for rising-onset stimuli that exhibited $20 \%$ to $30 \%$ responding to tone-lead stimuli (Subject 2 with long stimuli, Subject 3 with both stimuli), would have indicated a weaker response bias. We tested this response bias hypothesis in Experiment 2 by employing a relatively bias-free task to eliminate response criterion effects. Another explanation for the asymmetric psychometric functions is the possibility that the noise had been detectable only when a considerable portion of the noise onset was presented prior to tone onset, and therefore, was free from masking by the tone. This noise-detection hypothesis was based upon the finding that VOT boundary is inversely proportional to the relative intensity of the aspiration noise (Darwin \& Seton, 1983; Repp, 1979). The asymmetric psycho-

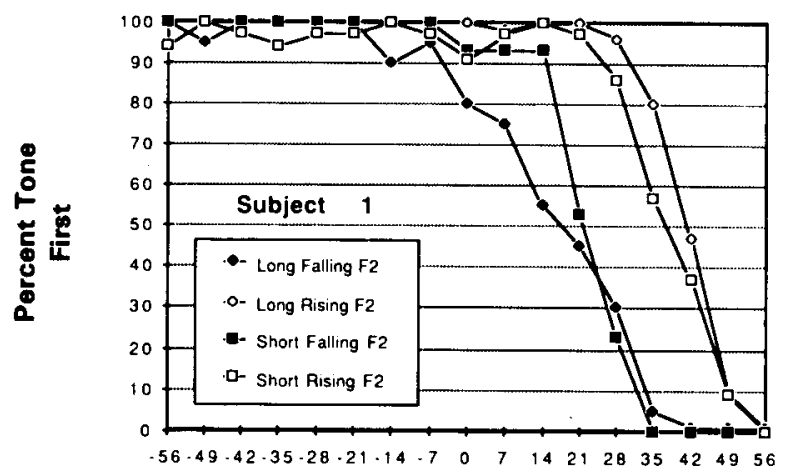

Relative Noise Onset Time in msec
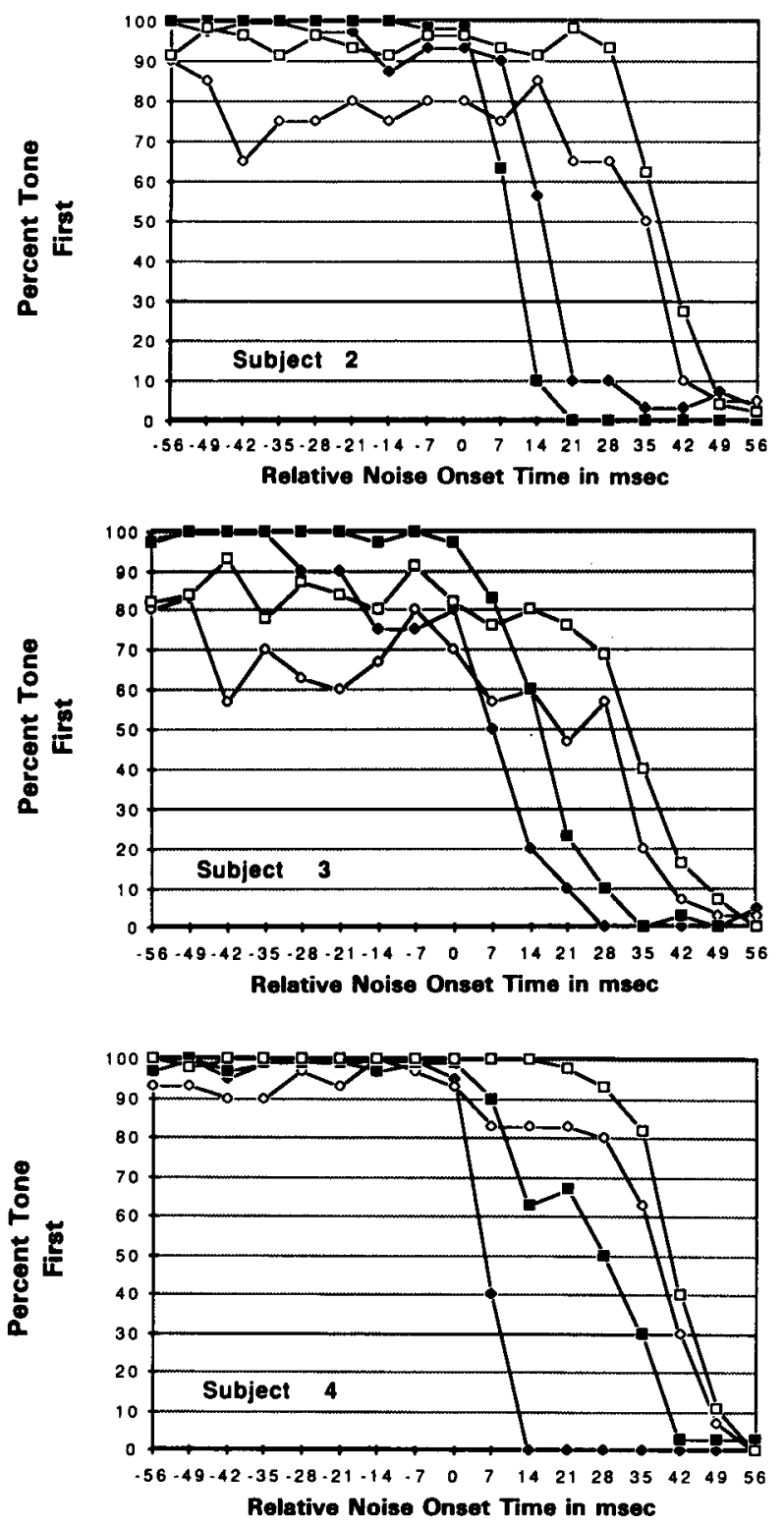

Figure 3. Actual psychometric function for the 4 subjects under the four conditions (two durations for two types of initial $f 2$ onset transitions) for Experiment 1. 
metric function here would have been due to a dominant perception of the tone at all onset asynchronies except when the noise was clearly detected or perceived at onset. In Experiment 3, we directly evaluated the noise detection hypothesis.

\section{EXPERIMENT 2 DIFFERENTIAL TOT THRESHOLDS}

In Experiment 2, we used a relatively bias-free psychophysical procedure to measure difference thresholds (DLs) (rather than absolute thresholds) for temporal order identification both with and without an initial burst of noise. In this experiment a two-interval temporal forced choice (2IFC) procedure was used to measure separately the DL for noise- and tone-lead conditions. The subjects always were instructed to indicate which of two stimuli had the longer onset difference. Within a block of trials, the standard stimulus had the shorter onset difference, which was either 0 or $7 \mathrm{msec}$. These standard stimuli were paired randomly with all stimuli that had greater onset differences. The use of two standard stimuli was intended to prevent the subjects from performing the task on the basis of some subtle characteristic of a single, fixed standard. If only the 0 -msec standard were used, the subjects might have been able to perform the task by detecting a lack of synchrony in onset. This detection cue was eliminated by also using the 7-msec stimulus that should have been supraliminal for detecting onset differences.

Comparison of the thresholds for the two standards allowed us to evaluate relative versus absolute stimulus processing. If the DL for the 7-msec standard was equal to or slightly greater than the DL for the 0-msec standard, the discrimination must have been based upon some form of a relative or proportional sensitivity, such as that described by Weber's law. However, if the 0 - and 7-msec thresholds were approximately equal in absolute location, then both thresholds probably were based upon a single distinctive perceptual characteristic or qualitative change in perception at that location. Such a fixed perceptual characteristic might serve as a basis for categorical perception with acoustic stimuli (Pastore et al., 1977), and might also represent an acoustic basis for the voicing boundary with synthetic speech continua.

The 2IFC procedure is relatively insensitive to response biases (Egan, 1975; Green \& Swets, 1966), such as those that might have contributed to the results in Experiment 1. If the subjects now exhibited similar, sharp thresholds for both noise and tone lead, we could conclude that the asymmetric TOJ results in Experiment 1 were due to response bias. If the subjects exhibited noise lead thresholds similar to Experiment 1 and the absence of thresholds for tone lead conditions, then the asymmetric thresholds found in Experiment 1 would represent actual differences in the sensory or perceptual analysis of the stimuli.

One drawback to the 2IFC procedure is that it measures a single threshold which represents the smallest DL for the given task and subject conditions. Thus, if there existed a highly salient perceptual discontinuity at a tem- poral onset longer than the DL, there would be no indication in the data of this supraliminal change in perceptual characteristic. It also is possible that a relatively naive subject may not be attuned to the reliable basis for a given perceptual discontinuity, and may thus exhibit a significantly larger DL.

Finally, the initial release burst is a strong cue for place of articulation (Blumstein \& Stevens, 1981), and typically is included in the synthetic continua employed in studying VOT voicing contrast boundaries. Hirsh (1959) investigated the importance of a noise burst as one of the two components in a temporal order identification task, but the effects of an added initial noise burst on an existing temporal order task had not been investigated by anyone. Therefore, the conditions for Experiment 2 were run with the stimuli from Experiment 1 both in isolation and with an initial burst of noise added. Comparison of the results from conditions differing only in the initial burst allowed us to evaluate the effect of an initial noise burst on TOJ.

\section{Method}

The four conditions from Experiment 1 were converted into eight conditions by creating separate tone-lead and noise-lead versions of each. There was a burst and a no-burst version of each of these eight conditions. Different bursts were employed with falling- and rising-onset stimuli. The falling stimulus burst was based upon the characteristics of natural release bursts for velar consonants (Zue, 1976) and was a 25-msec segment of 2-4-kHz filtered white noise. The rising burst, patterned after natural release bursts for labial consonants, was a 15-msec segment of $0.8-1.6-\mathrm{kHz}$ filtered white noise. The noise bursts began and ended on waveform zero-crossings and had 4-msec rise and fall times. Both initial bursts were $72 \mathrm{~dB}$ SPL (fast scale of sound-level meter). TOJ always was measured from the onset of the leading tone or noise, and thus the measurement was independent of any preceding burst. The ISI and response interval were 350 and $3,500 \mathrm{msec}$, respectively.

In every random sequence, each of the two standard stimuli ( $0 \mathrm{msec}$ and $7 \mathrm{msec}$ ) was paired with each longer stimulus a total of six times (three times each as the first and second stimulus of the trial). There were two random sequences for each condition. Every condition was run until all subjects had completed a minimum of four repetitions of each sequence (at least 48 trials per comparison). All long stimulus conditions were completed before the short stimulus conditions were run. Sequences for both tone and noise lead with both rising- and falling-onset stimuli were run within any given session. Subjects always were informed of the nature of the comparison for the given sequence. ${ }^{4}$

A least squares analysis of a $z$-score transformation was used to estimate the threshold for each psychometric function with $\mathbf{0}$ - and 7 -msec standards. This analysis is based upon the assumption that a cumulative Gaussian distribution describes the psychometric function in the threshold region between chance $(50 \%)$ performance and perfect discrimination, with threshold defined as $75 \%$ discrimination performance. The least squares analysis was performed on the pooled results of two consecutive blocks of trials per subject, and thus was based upon 12 trials per stimulus. These separate threshold estimates were used to compute a mean and standard error for each subject under every stimulus condition. The standard error provides a measure of the stability of the threshold measure, as well as a basis for estimating statistical significance."

\section{Results and Discussion}

Noise-lead. The mean (and standard error) of the threshold locations for the 0 - and 7-msec standards for 
the eight noise-lead conditions are summarized in the first two sections of Table 3 . The psychometric functions for the noise-lead stimuli all exhibited steep slopes.

The rising-onset stimuli exhibited a threshold located at a fixed, relatively long onset difference. In the absence of an initial burst, the rising-onset stimuli exhibited 33msec average thresholds, which were similar to the long thresholds found in Experiment 1. The thresholds for the 0 - and 7-msec standards were highly similar both within and across subjects. These results indicate that the subjects probably responded on the basis of a qualitative change in perception, rather than to a relative DL based upon a Weber's law type of relationship. The addition of the initial low-frequency burst increased the average TOJ for each condition by approximately $3 \mathrm{msec}$, although this small change was not consistent across subjects and certainly was not statistically significant. Finally, there was no difference between the short and long stimuli, so the small duration effects previously reported for TOJ with tones (Table 2) and synthetic voicing continua (Table 1) were not replicated. We conclude from these results that there is some type of threshold or qualitative change in perception for the rising-onset, noise-lead stimuli at approximately 33-36 msec, and that this threshold probably is independent of overall stimulus duration.

The falling-onset stimuli exhibited relative DLs at variable locations that were significantly shorter than the identical conditions with the rising-onset stimuli, but similar to the onset differences reported for tone stimuli by $\mathrm{Pa}$ store et al. (1982; see Table 2). For all of the current

Table 3

Experiment 2 Threshold Locations

\begin{tabular}{|c|c|c|c|c|c|c|c|c|}
\hline & \multicolumn{4}{|c|}{ Short (150 msec) Duration } & \multicolumn{4}{|c|}{ Long (300 msec) Duration } \\
\hline & $\overline{0-\mathrm{msec}}$ & Stand. & 7-mse & Stand. & 0 -mse & Stand. & 7-mse & Stand. \\
\hline \multicolumn{9}{|c|}{ Rising-Onset Stimuli with Noise-Lead } \\
\hline \multicolumn{9}{|l|}{ No Burst } \\
\hline $\begin{array}{l}\text { Subject 1: } \\
\text { Subject 2: } \\
\text { Subject 3: } \\
\text { Subject 4: }\end{array}$ & $\begin{array}{l}35.8 \\
34.8 \\
30.3 \\
31.4\end{array}$ & $\begin{array}{l}(1.8) \\
(3.4) \\
(2.1) \\
(1.7)\end{array}$ & $\begin{array}{l}34.7 \\
39.6 \\
30.0 \\
31.3\end{array}$ & $\begin{array}{l}(3.2) \\
(2.5) \\
(1.5) \\
(1.7)\end{array}$ & $\begin{array}{l}32.7 \\
37.0 \\
31.2 \\
28.1\end{array}$ & $\begin{array}{l}(1.1) \\
(2.1) \\
(4.0) \\
(1.1)\end{array}$ & $\begin{array}{l}32.6 \\
36.5 \\
32.6 \\
28.0\end{array}$ & $\begin{array}{l}(2.3) \\
(3.1) \\
(4.3) \\
(1.4)\end{array}$ \\
\hline Mean: & 33.1 & (1.5) & 33.9 & (2.5) & 32.3 & $(2.1)$ & 32.4 & $(2.0)$ \\
\hline Cond. Mean: & \multicolumn{4}{|c|}{33.5} & \multicolumn{4}{|c|}{32.3} \\
\hline \multicolumn{9}{|l|}{ Burst } \\
\hline $\begin{array}{l}\text { Subject 1: } \\
\text { Subject 2: } \\
\text { Subject } 3 \text { : } \\
\text { Subject } 4:\end{array}$ & $\begin{array}{l}36.2 \\
37.8 \\
33.0 \\
35.6\end{array}$ & $\begin{array}{l}(1.5) \\
(1.7) \\
(1.2) \\
(2.7)\end{array}$ & $\begin{array}{l}37.9 \\
36.9 \\
35.0 \\
38.6\end{array}$ & $\begin{array}{l}(2.3) \\
(0.6) \\
(2.9) \\
(2.7)\end{array}$ & $\begin{array}{l}32.2 \\
35.6 \\
31.3 \\
40.0\end{array}$ & $\begin{array}{r}(12.5) \\
(4.0) \\
(2.3) \\
(1.4)\end{array}$ & $\begin{array}{l}38.7 \\
40.4 \\
30.1 \\
38.8\end{array}$ & $\begin{array}{l}(6.9) \\
(2.9) \\
(1.0) \\
(3.7)\end{array}$ \\
\hline Mean: & 35.7 & $(1.2)$ & 37.1 & $(0.9)$ & 34.8 & (2.3) & 37.0 & (2.7) \\
\hline Cond. Mean: & \multicolumn{4}{|c|}{36.4} & \multicolumn{4}{|c|}{35.9} \\
\hline
\end{tabular}

Falling-Onset Stimuli with Noise-Lead

\begin{tabular}{|c|c|c|c|c|c|c|c|c|}
\hline \multicolumn{9}{|l|}{ No Burst } \\
\hline Subject 1: & 9.2 & (1.5) & 18.0 & $(1.7)^{*}$ & 14.8 & (1.6) & 21.1 & $(1.7)^{*}$ \\
\hline Subject 2: & 13.1 & (1.6) & 15.7 & $(2.0)$ & 14.4 & (1.4) & 18.6 & $(3.4)$ \\
\hline Subject 3: & 5.3 & (0.6) & 14.5 & $(1.4)^{*}$ & 7.9 & (1.4) & 15.7 & $(0.9)^{*}$ \\
\hline Subject 4: & 5.5 & $(0.6)$ & 12.7 & $(-)^{*}$ & 8.3 & (2.1) & 15.9 & $(2.8)^{*}$ \\
\hline Mean: & 8.3 & (2.1) & 15.2 & $(1.3)^{*}$ & 11.4 & (2.2) & 17.8 & $(1.5)^{*}$ \\
\hline Cond. Mean: & \multicolumn{4}{|c|}{11.8} & \multicolumn{4}{|c|}{14.6} \\
\hline \multicolumn{9}{|l|}{ Burst } \\
\hline Subject 1: & 15.8 & (3.9) & 22.2 & $(1.6)^{*}$ & 21.3 & (1.7) & 24.2 & $(1.8)^{*}$ \\
\hline Subject 2: & 13.5 & (1.4) & 17.1 & $(0.1)^{*}$ & 12.6 & (3.6) & 22.6 & $(1.4)^{*}$ \\
\hline Subject 3: & 10.1 & (2.4) & 17.5 & $(1.3)^{*}$ & 12.9 & (1.3) & 22.3 & $(1.1)^{*}$ \\
\hline Subject 4: & 11.9 & (2.7) & 21.7 & $(1.8)^{*}$ & 9.7 & (1.3) & 21.8 & $(2.3)^{*}$ \\
\hline Mean: & 12.8 & (1.4) & 19.6 & $(1.6)^{*}$ & 14.1 & $(2.9)$ & 22.7 & $(0.6)^{*}$ \\
\hline Cond. Mean: & \multicolumn{4}{|c|}{16.2} & \multicolumn{4}{|c|}{18.4} \\
\hline
\end{tabular}

Tone-Lead Results (Subject 1 only)

\begin{tabular}{lrlllrlll} 
Rise-No B. & 24.3 & $(5.6)$ & 28.6 & $(3.8)$ & 13.2 & $(1.4)$ & 20.2 & $(1.7)$ \\
Rise-Burst & 27.4 & $(4.5)$ & 29.3 & $(4.2)$ & 38.7 & $(3.7)$ & 39.4 & $(3.8)$ \\
Fall-No B. & 7.5 & $(0.6)$ & 17.0 & $(1.1)^{*}$ & 7.0 & $(1.1)$ & 15.2 & $(2.3)^{*}$ \\
Fall-Burst & 11.2 & $(5.0)$ & 18.5 & $(5.7)$ & 13.6 & $(2.8)$ & 16.2 & $(2.7)$ \\
\hline
\end{tabular}

*See Footnote 5. 
stimuli there was an average difference of approximately $7 \mathrm{msec}$ between the 0 -msec and 7-msec standards, indicating that the subjects were responding on the basis of a relative threshold. Overall, this difference in TOJ for the two standards was statistically significant for all conditions, and the differences were statistically significant for all subjects except for Subject 2 with the burst absent.

Doubling stimulus duration for falling-onset stimuli increased TOJ for all subjects by at least the 1.4- to 7-msec change in VOT found for doubling the duration of speech stimuli (see Table 1). Overall, this difference was significant (one-tail comparison) only for the 7-msec standard, whereas the specific differences were significant for almost half of the comparisons. The addition of the initial burst increased the average threshold by $4 \mathrm{msec}$. This increase in threshold was statistically significant (one-tail comparison) for 3 of the 4 subjects. The combined effects of burst and duration were significant for all but one condition (Subject 2 with the 0 msec standard).

We found that in contrast to these short, proportional thresholds for the falling-onset stimuli, the rising-onset stimuli exhibited a single, relatively long threshold along the onset asynchrony continuum. If a similar qualitative change in perception existed for the falling-onset continuum at longer onset differences corresponding to velar voicing boundaries, that qualitative change would not have been identified by the psychophysical procedures used in Experiments 1 and 2. Those procedures determined the DL closest to simultaneous onset. This psychophysical problem was addressed in Experiment 4.

Tone-lead stimuli. All subjects had complained repeatedly that the tone-lead conditions were very difficult. With the exception of Subject 1, our most experienced psychophysical listener (and then only after considerable practice), the tone-lead psychometric functions either remained near chance or had an extremely shallow slope covering the full range of stimulus values (thus not permitting reliable threshold estimates). Since the 2IFC procedure is relatively bias free, we conclude that the absence of any measurable TOJ for tone-lead stimuli with these subjects was due to the inherent difficulty of the discrimination, and not to any simple response bias.

The threshold locations for Subject 1 are summarized in the final section of Table 3 . In all cases, the threshold location was longer for the 7-msec standard than for the 0 -msec standard, and all thresholds were longer for conditions with an initial burst than for the equivalent conditions without the burst. Although consistent with the results for noise-lead stimuli, these observations must be interpreted with caution, since the results are for only 1 subject and less than half of the differences are statistically significant due to large standard errors, indicating a high degree of variability.

\section{EXPERIMENT 3 RELATIVE NOISE AMPLITUDE}

In the first two experiments, we were unable to measure tone-lead TOJ for rising stimuli (at least not within the range of the stimulus values employed). TOJ for the noise-lead conditions were at onset differences longer than those typical of simple tone stimuli, and equal to typical VOT voicing boundaries for English stop consonants (although somewhat longer than typical for labial stops). Following Experiment 1, we had conjectured that both the absence of measurable TOJ for tone lead and the magnitude of TOJ for noise lead may have been based upon a lack of ability either to detect the noise or to recognize specific characteristics of the noise. If the noise was poorly detected, then all tone-lead stimuli (which differ only in degree of delayed noise onset) would have been perceptually equivalent in terms of noise characteristics, and thus poorly discriminated. In the noise-lead conditions, only long segments of noise presented in isolation would have achieved the level of perceptual distinctiveness required for reliable identification of order. If these conjectures are valid, increasing the relative amplitude of the noise component should have produced a measurable TOJ for tone-lead stimuli and a reduced TOJ for noise-lead stimuli. Experiment 3 provided an evaluation of these conjectures.

\section{Method}

The amplitude of the noise component was varied relative to the 71.5- $\mathrm{dB}(\mathrm{A})$ noise component in the long rising stimuli from $\mathrm{Ex}$ periment 2. Three noise-lead conditions $\left(+10_{-}, 0-\right.$, and $-10-\mathrm{dB}$ noise amplitude) and two tone-lead conditions $(+10-$ and $0-\mathrm{dB}$ noise amplitude) were run. Each of the initially naive subjects was given a 2-h practice session with the original ( $0-\mathrm{dB}$ noise component) stimuli prior to any data collection. Each subject then made a minimum of 80 observations per data point for each condition. The $0-\mathrm{dB}$ conditions represented replications of Experiment 2 with new subjects.

\section{Results and Discussion}

Tone-lead stimuli. The tone-lead threshold locations are summarized in the first section of Table 4 . Subject 7 produced measurable thresholds for both 0 - and $+10-\mathrm{dB}$ noise amplitude, with the thresholds for $+10-\mathrm{dB}$ noise amplitude far more stable, as indicated by the smaller standard error measures. For the $0-\mathrm{dB}$ relative noiseamplitude condition, the other 3 subjects produced psychometric functions that never exceeded $75 \%$. Two of these 3 subjects produced measurable thresholds with the noise amplitude at $+10 \mathrm{~dB}$, although most of the thresholds were highly variable in location across blocks of trials.

These results replicated the basic finding in Experiments 1 and 2 that the tone-lead discrimination was more difficult than the noise-lead discrimination. The results also indicated that noise amplitude is important in the tone-lead condition, since amplifying the noise by $10 \mathrm{~dB}$ allowed Subjects 5 and 6 to perform the task and Subject 7 to do so with greater reliability. If Subjects 5 and 6 had not been able to recognize the onset of the noise at $0-\mathrm{dB}$ relative onset, and Subject 7 had not been able to do so very reliably, the $10 \mathrm{~dB}$ increase in noise amplitude could have better defined the noise onset for these subjects, and thus could have produced the observed results. This conjecture could explain our tone-lead results where the tone 
Table 4

TOJ as a Function of Noise Amplitude

\begin{tabular}{|c|c|c|c|c|c|c|c|}
\hline \multirow[b]{2}{*}{ Subject } & \multirow[b]{2}{*}{ Standard* } & \multicolumn{2}{|c|}{$-10 \mathrm{~dB}$} & \multicolumn{2}{|c|}{$0 \mathrm{~dB}$} & \multicolumn{2}{|c|}{$+10 \mathrm{~dB}$} \\
\hline & & $M$ & $S E$ & $M$ & $S E$ & $M$ & $S E$ \\
\hline \multicolumn{8}{|c|}{ Tone Lead } \\
\hline \multirow[t]{2}{*}{5} & 0 & & & & & 49.1 & 8.4 \\
\hline & 7 & & & & & 49.5 & 0.6 \\
\hline \multirow[t]{2}{*}{6} & 0 & & & & & 33.2 & 10.7 \\
\hline & 7 & & & & & 28.1 & 11.4 \\
\hline \multirow[t]{2}{*}{7} & 0 & & & 40.5 & 4.1 & 38.5 & 2.9 \\
\hline & 7 & & & 42.2 & 4.4 & 41.9 & 1.4 \\
\hline \multicolumn{8}{|c|}{ Noise Lead } \\
\hline \multirow[t]{2}{*}{5} & 0 & 35.2 & 1.2 & 46.6 & 4.4 & 45.1 & 6.9 \\
\hline & 7 & 30.7 & 6.3 & 41.0 & 4.4 & 42.9 & 5.0 \\
\hline \multirow[t]{2}{*}{6} & 0 & 31.3 & 2.5 & 30.2 & 7.9 & 33.7 & 8.8 \\
\hline & 7 & 30.6 & 2.4 & 29.6 & 4.3 & 32.9 & 6.0 \\
\hline \multirow[t]{2}{*}{7} & 0 & 32.6 & 1.5 & 31.1 & 2.9 & 33.4 & 1.1 \\
\hline & 7 & 25.3 & 2.8 & 32.5 & 3.8 & 34.0 & 0.4 \\
\hline
\end{tabular}

*In milliseconds.

may have masked the onset of the noise. However, this conjecture cannot explain the lack of effect of noise amplitude for the noise-lead condition (described next).

Noise-lead stimuli. The mean (and standard error) of threshold locations for the noise-lead stimuli for 3 subjects are summarized in the second section of Table 4; Subject 8 failed to exceed $75 \%$ discrimination performance for any stimulus comparison. Some of the threshold estimates for the other subjects were highly variable, as indicated by the large standard errors.

The results provide a replication of Experiment 2 for the rising-onset stimuli with noise lead. The thresholds for the 0 - and 7-msec standards were all equivalent, and the majority of thresholds were located between 30 - and 40 -msec onset differences. The finding of equivalent thresholds for the two standards again indicated that the subjects probably were responding to a single qualitative change in perception. Although half of the comparisons between -10 - and $0-\mathrm{dB}$ noise-amplitude conditions exhibited moderate changes in threshold location (Subject 5 with both standards, and Subject 7 with the 7-msec standard), one or both of the threshold estimates was not stable, as demonstrated by the large standard errors. Furthermore, the change in threshold for these three conditions were opposite to the change in VOT boundary as a function of noise amplitude and opposite to the prediction of our noise-detection hypothesis. All of the comparisons between the 0 - and $+10-\mathrm{dB}$ noise-amplitude conditions were equivalent. We therefore conclude that noise amplitude did not significantly alter the location of TOJ threshold in the predicted manner, and probably had no effect on threshold location.

The absence of a trading between noise intensity and onset delay replicated previous findings that TOJ is independent of component amplitude (Table 2), and seems to be in contrast to the shift in VOT boundary with changes in aspiration noise intensity (Table 1). However, one major difference in stimulus properties may account for these contrasted findings. In the Repp (1979) study, the noise was presented only until the onset of voicing, and thus ranged in duration from 8 to $44 \mathrm{msec}$ in 4-msec steps. All of these different noise durations were within the limits of integration of the auditory system, and thus differed in effective amplitude as a function of duration (or VOT) within each nominal noise-amplitude condition. For measures of both absolute threshold and (supraliminal) loudness, the effect of auditory integration is a trading of duration and average instantaneous intensity to yield a constant total stimulus magnitude $(I * t=\mathrm{k})$. At short values of VOT, the noise might have been subliminal in terms of detection (or the recognition of specific characteristics), whereas the longer (thus more intense) noise may have been supraliminal for the critical perceptual property. Amplifying or attenuating the instantaneous noise intensity, then, would have altered the threshold location measured in terms of noise duration and defined by VOT. If we assume that $I * t$ defines a threshold value, and that threshold is measured in terms of $t$ for constant $I$, then any change in $I$ must result in a change in measured threshold, $t$. We note that the (as yet undefined) critical noise property must be defined relative to the voiced component, since (1) isolated noise stimuli varying in duration do not exhibit a sharp threshold in the range of onsets typical for TOT and VOT boundaries (J. D. Miller et al., 1976), and (2) aspiration noise substituted for all formant transitions does not produce the perception of voicelessness (Liberman et al., 1958).

In our noise-lead conditions, the noise duration always equaled the total stimulus duration, and thus did not vary in amplitude with changes in onset (created by cutting back the onset of the tonal component). Therefore, altering the intensity of the noise component in the current study might have altered some recognition properties of the noise, but did not alter the trading relation described above.

\section{EXPERIMENT 4 LONGER TOJ FOR FALLING NOISE LEAD STIMULI}

The noise-lead conditions with falling-onset stimuli in Experiment 2 yielded TOJ values that were small and that seemed to indicate a DL relative to the given stimulus standard. The 2IFC psychophysical procedure with 0 - and 7msec standards measured only the smallest changes necessary to perform the task. Thus, this procedure did not test for the possibility of a qualitative change in perception at longer onset differences that would be more appropriate for voicing contrast (assuming that such a change exists). Such a longer perceptual threshold might be demonstrated by using the stimuli with the longest onset difference ( 49 and $56 \mathrm{msec}$ ) as the standard stimuli in the 2IFC discrimination task. This task identified the longest onset stimuli that are discriminably shorter than the two stimuli with the maximum onset differences used in the 
current study. The principles described above for evaluating a fixed threshold versus relative discrimination applied to this modified task.

\section{Method}

The noise-lead condition for the long, falling-onset stimuli from Experiment 2 was replicated, substituting as standards the stimuli with 56- and 49-msec onset differences for the 0 - and 7-msec onset stimuli.

\section{Results and Discussion}

Table 5 contains the estimates of threshold locations and DLs relative to the 49- and 56-msec standards for 3 subjects: Subject 7 failed to discriminate any stimulus comparisons at better than chance. In Experiment 2, with the rising-onset stimuli, all subjects exhibited relatively long DLs at a fixed onset location of approximately 33 to $36 \mathrm{msec}$, with the falling-onset stimuli, the subjects exhibited smaller DLs, which approximated a constant stimulus change rather than a constant location. In this experiment, it would appear that the falling-stimulus DLs were at a fixed 33-34-msec location for Subject 5, at a constant 13.75-msec DL for Subject 6, and at neither for Subject 8 . However, this observation may be misleading, since five of six conditions either yielded a threshold at a fixed 33-36-msec location or provided evidence for such a fixed perceptual boundary.

Four of the six thresholds are located in the 33-36-msec range identified in Experiment 2 for the rising-onset stimuli. The 42.2-msec threshold location for Subject 6 with the 56-msec standard was based on two blocks of trials with a threshold at $35.4 \mathrm{msec}$; the remaining blocks of trials exhibited smaller DLs (threshold located at 43.9 [2.0] msec, yielding a DL of 12.1). This pattern of results would seem to indicate that Subject 6 first responded on the basis of the 33-36-msec fixed-location boundary before learning to perform the task with the 56-msec standard on the basis of more subtle stimulus differences. Subject 8 , who had not been able to perform the task in Experiment 3, clearly required a large stimulus difference to perform the task with the 49-msec standard. These results thus are quite consistent with the conclusion that there is a perceptual boundary for falling-onset (as well as rising-onset) stimuli with noise lead at an onset difference of approximately $33-36 \mathrm{msec}$.

\section{GENERAL DISCUSSION}

\section{Threshold Location}

Earlier investigations of TOJ have consistently found perceptual thresholds or boundaries that ranged from 4

Table 5

TOJ for Falling Onset Stimuli

\begin{tabular}{cccccccc}
\hline & \multicolumn{4}{c}{ 49-msec Standard } & & \multicolumn{3}{c}{ 56-msec Standard } \\
\cline { 2 - 4 } \cline { 6 - 8 } Subject & Locat. & $S E$ & DL & & Locat. & $S E$ & DL \\
\hline 5 & 33.5 & 3.9 & 15.5 & & 33.3 & 1.3 & 22.7 \\
6 & 35.5 & 1.6 & 13.7 & & 42.2 & 2.4 & 13.8 \\
8 & 22.6 & 1.3 & 25.4 & & 33.8 & 1.6 & 22.2 \\
\hline
\end{tabular}

to $24 \mathrm{msec}$ for stationary tones and from 18 to $29 \mathrm{msec}$ for tones with dynamic onsets or transitions (Table 2). In the present study with dynamic-onset, mixed-spectrum stimuli, we found a significant asymmetry in the perception of TOJ for tone- and noise-lead stimuli. For the stimuli with rising-onset transitions, we have found DLs that ranged from 25 to 46 msec, with most thresholds located between approximately 32 and $36 \mathrm{msec}$. In addition, there was a strong indication that these DLs were fixed in location along the onset continuum, rather than fixed in proportional size relative to the given standard, as would be expected from a Weber's law acoustic relationship.

With the falling-onset stimuli, the thresholds for perception of briefest onset differences ranged from 5 to $22 \mathrm{msec}$. However, when discrimination was relative to the longer onset differences (Experiment 4), there was a very strong indication of a qualitative change in perception located in the 33- to 36-msec range of onset differences for the falling-onset stimuli.

A fixed DL location would imply some sort of a qualitative change in perception at that stimulus location, although the nature of any such qualitative change in temporal order perception has not yet been identified. It is possible that this qualitative perceptual change, located in the general range of VOT voicing boundaries summarized in Table 1, may serve as the natural perceptual discontinuity from which the perception of change in voicing quality developed. However, we have now demonstrated only a very loose parallel between TOT and VOT continua in terms of some boundary conditions. We must better understand the nature of TOJ before being able to explore seriously any possible relationships between TOJ and VOT.

\section{Burst Effects}

In Experiment 2, DLs were measured for the identical conditions both without and with a noise burst at onset. The initial noise burst shifted the location of the DL to longer onset differences relative to the onset of the basic stimuli (excluding the noise burst). With both long and short rising-onset stimuli, the noise burst increased TOJ an average of about $3.3 \mathrm{msec}$. With the falling-onset stimuli, the noise burst increased TOJ by an average of $4.2 \mathrm{msec}$, which, with the smaller relative thresholds, was a proportionally larger change. Between subjects, each of the increases in threshold due to an initial noise burst was statistically significant for three out of four comparisons for both rising- and falling-onset stimuli. Clearly, the initial noise burst makes the temporal order discrimination task more difficult. Although the magnitude of this threshold increase was small, it was at least equal in magnitude to the typically reported changes in voicing boundary due to the doubling of stimulus duration.

The initial noise burst probably acts as a type of forward-masking stimulus, interfering with either the detection or recognition of stimulus characteristics at onset. Although masking usually is specified in terms of the change in the intensity of the stimulus necessary to cor- 
rect for the masking, it is perfectly logical to measure masking in terms of a temporal variable. Since masking can alter both the relative DLs for tones and fixed thresholds for speech, forward-masking effects should be found for both the brief, relative DLs found for the fallingonset stimuli and the long, fixed-location DLs found for the rising-onset stimuli. If the initial burst does function as a type of forward masker, then increasing the intensity of the burst should cause a greater shift in threshold or boundary location. Since our initial noise bursts were weak, relative to the release bursts found with natural velar and alveolar stop consonants, we may have underestimated the role played by the release burst.

\section{Modes of Perception}

It is our experience that while performing psychophysical tasks with complex stimuli, subjects sometimes exhibit different types of perceptual responding depending upon their previous experience or practice, the specific task and stimuli employed, and their expectations about the nature of the stimuli. On some tasks, both naive and psychophysically experienced subjects exhibit identical results. On other tasks, those with a fixed set of stimuli and procedures, practiced subjects exhibit significantly lower perceptual thresholds or boundary locations (Watson \& Kelly, 1981). Finally, subjects whose psychophysical experience was seemingly unrelated to the given stimuli and task exhibit either smaller thresholds or significantly different patterns of perception than naive subjects (Pastore, Morris, Logan, \& Layer, 1986). Clearly, practice or experience can allow subjects access to different stimulus characteristics in performing a given task.

We would describe naive and experienced subjects as operating in different modes of perception, where a perceptual mode represents a level of stimulus processing. The notion of modes of perception is not new, but it has usually been used to imply distinctively different perceptual systems, such as auditory and phonetic modes of processing (Best, Morrongielo, \& Robson, 1981; Fujisaki \& Kawashima, 1971; Pisoni \& Lazarus, 1973; Werker \& Logan, 1985). We are using the term mode in a different, although not necessarily incompatible, manner.

In the laboratory, a subject must approach each psychophysical task with a degree of uncertainty concerning the importance of stimulus parameters and task demands (Pastore, 1981). That degree of uncertainty will be determined by the stimulus characteristics, by the subject's working knowledge of those characteristics, and by the nature of the task. Naive subjects operate under high uncertainty and tend to operate in a global mode, concentrating primarily on a limited set of familiar, general stimulus characteristics. If the stimuli used in a laboratory are perceived as speech, the cues that determine perception will be those most important in differentiating familiar linguistic units with highly variable stimuli.

Practiced, or experienced, subjects tend to respond in an analytic mode. During the brief existence of the stimulus trace, a practiced subject may be able to optimize dis- crimination performance by attending to those subtle cues which best allow them to differentiate between stimuli. Experience also may allow subjects to respond with a different weighting of perceptual characteristics, as has been demonstrated in several developmental studies of speech contrasts (Best et al., 1981; Simon \& Fourcin, 1978). Experience with a language also may result in a subject's learning to ignore certain perceptual attributes while attending to others, thus creating a selective mode of response for the given language. If the subject is naive to the language used to generate the stimuli, the perceived cues may be unimportant or even inappropriate for distinguishing the phonetic categories in that language.

Our conception of global and analytic modes of perception is similar to the two modes of perception proposed by Foster and others (see Foster, 1983) for visual pattern perception. According to Foster, discrimination performance is characterized by relatively coarse, discrete processes in high-uncertainty situations in which attention is distributed over a number of stimulus elements and processing time is restricted. This discrete processing mode is contrasted with smooth, continuous, fine-grain processing in low-uncertainty situations in which there are a restricted number of stimuli and processing time is unlimited. Foster cites similarities between the discrete mode of perception and categorical perception for speech stimuli. In many respects, these modes of perception also are similar to the qualitative changes in performance described in the attention literature, where practice in the search for features changes from a type of limitedcapacity, conscious, serial decision making to fast, automatic, parallel detection of features (e.g., Shiffrin \& Schneider, 1977; Treisman \& Gelade, 1980).

Empirical support for global and analytic modes can be found in the study of within-category discrimination of unvoiced stop consonants varying in VOT using naive and experienced subjects (Pisoni \& Lazarus, 1974; Samuel, 1977). For subjects with little experience (thus, in a high-uncertainty situation), stimuli differing by $10 \mathrm{msec}$ were discriminated at chance levels. Experienced subjects discriminated the identical stimuli at better than chance levels, with their performance appearing to follow the general prediction of a constant Weber fraction. It is likely that the experienced subjects are attending to different (but possibly overlapping) sets of stimulus attributes.

These modes of perception are consistent with the performance of subjects in the current and previous TOJ experiments. TOJ for stationary tones seems to be highly dependent upon mode of perception, exhibiting relatively discrete shifts in levels of task performance based upon prior experience. TOJ for naive subjects typically is in the range of 100 to $150 \mathrm{msec}$. After a few hours of experience with the basic task, TOJ for the same subjects decreases to an intermediate range before reaching the range reported in Table 2 (Pastore et al., 1982). With extensive practice, subjects exhibit a Weber type of discrimi- 
nation function for stimuli with short onset differences (Kewley-Port, Watson, \& Foyle, in press).

In Experiment 2, the subjects were probably operating in a global mode for the rising-onset stimuli and exhibited relatively long DLs based upon a fixed location in the onset continuum. With the falling-onset stimuli, the subjects were able to respond to more subtle stimulus characteristics, which resulted in small relative DLs.

We can provide a post hoc analysis of our stimuli to explain the two patterns of responding. In the rising-onset stimuli, the critical stimulus changes were located in the spectral center of the stimuli (Figure 1), and subtle onset characteristics may have been difficult to detect. As a result, global characteristics of the stimuli would seem to dominate performance, yielding long, fixed-location DLs. In the falling-onset stimuli, the critical stimulus properties for the 0 - and 7-msec standards were located at frequencies considerably higher than any other portion of the stimuli, and thus relatively free from masking, allowing the subjects to respond to more subtle stimulus characteristics. When the task was to discriminate these falling-onset stimuli using the 49- and 56-msec standards, the critical stimulus properties now occurred closer to the final $f 2$ frequency, which tended to force the subjects into a more global mode of responding.

The existence of analysis modes, and the relationship between different analysis modes and measurements of boundary location, suggests that the evaluation of all acoustic phenomena and speech contrasts must consider the level of analysis appropriate for the subject in the given task.

\section{Conclusion}

TOJ for simple acoustic stimuli can be rejected as a basis for the perception of voicing contrasts because its location always is significantly shorter than the voicing boundary for various types of synthetic speech continua. However, onset differences for more complex stimuli tend to exhibit a stable threshold that is similar in location to the voicing boundary for alveolar and velar stimuli. The addition of a strong burst of noise at onset shifts TOJ to a somewhat longer onset delay. This threshold did not exhibit the small change in boundary location found for speech stimuli that varied in duration. This threshold also did not exhibit the change in location as a function of noise component intensity, although the effect of aspiration noise intensity found with synthetic speech stimuli may be related to the changes in aspiration noise duration that are coupled with the manipulation of VOT. When the experience, expectations, attentional strategies of subjects, and the demands of the psychophysical tasks, are taken into consideration, it seems quite possible that limitations on the perception of the temporal order of onset of aspiration and voicing components in stimuli may contribute in a significant fashion to the perception of voicing contrast for initial stop consonants of English.

\section{REFERENCES}

Best, C. T., Morrongielo, B., Robson, R. (1981). Perceptual equivalence of acoustic cues in speech and nonspeech perception. Perception \& Psychophysics, 29, 191-211.

Blumstein, S. E., \& Stevens, K. N. (1981). The search for invariant acoustic correlates of phonetic features. In P. D. Eimas \& J. L. Miller (Eds.), Perspectives in the study of speech (pp. 1-38). Hillsdale, NJ: Erlbaum.

Darwin, C. J., \& Pearson, M. (1982). What tells us when voicing has started? Speech Communication, 1, 29-44.

Darwin, C. J., Seton, J. (1983). Perceptual cues to the onset of voiced excitation in aspirated initial stops. Journal of the Acoustical Sociery of America, 74, 1126-1135.

EGAN, J. P. (1975). Signal detection theory and ROC analysis. New York: Academic Press.

Foster, D. H. (1983). Visual discrimination, categorical identification, and categorical rating in brief displays of curved lines: Implications for discrete encoding processes. Joumal of Experimental Psychology: Human Perception \& Performance, 9, 785-806.

Fujisakı, H., \& Kawashima, T. (1971). A model of the mechanisms for speech perception quantitative analysis of categorical effects in discrimination. Annual Report of the Engineering Research Institute (Faculty of Engineering, University of Tokyo), 30, 59-68.

GreEN, D. M., SwETs, J. A. (1966). Signal detection theory and psychophysics. New York: Wiley.

Hillendrand, J. (1984). Perception of sine-wave analogs of voice onset time stimuli. Joumal of the Acoustical Society of America, 75, 231-240.

HIRSH, I. J. (1959). Auditory perception of temporal order. Joumal of the Acoustical Society of America, 31, 759-767.

JoNGMAN, A. (1986). Effects of speaking rate on the perception of syllable-initial stop consonants. Journal of the Acoustical Society of America, 75, 59. (Abstract)

Kenting, P. (1984). Phonetic and phonological representation of stop consonant voicing. Language, 60, 286-319.

Kelly, W. J., \& WATSON, C. S. (1986). Stimulus-based limitations on the discrimination between different temporal orders of tones. Journal of the Acoustical Society of America, 79, 1934-1938.

Kewley-Port, D., Watson, C. S., Foyle, D. C. (in press). Auditory temporal acuity in relation to category boundaries: Speech and non-speech stimuli. Journal of the Acoustical Society of America.

Liberman, A. M., Delattre, P. C., Cooper, F. S. (1958). Some cues for the distinction between voiced and voiceless stops in initial position. Language \& Speech, 1, 153-167.

Liberman, A. M., Mattingly, I. G. (1985). Motor theory of speech perception revisited. Cognition, 21, 1-36.

Lisker, L., A ABRAMSON, A. S. (1970). The voicing dimension: Some experiments in comparative phonetics. Proceedings of the 6ith International Congress of Phonetic Sciences, Prague, 1967 (pp. 563-537). Prague: Academia.

Lisker, L., Liberman, A. M., Erickson, D. M., Dechovitz, D., * MANDLER, R. (1977). On pushing the voice-onset-time (VOT) boundary about. Language \& Speech, 20, 209-216.

Massaro, D. W., Oden, G. (1980). Evaluation and integration of acoustic features in speech perception. Journal of the Acoustical Society of America, 67, 996-1013.

Miller, J. D., Wier, C. C., Pastore, R. E., Kelly, W. J., a DoolING, R. J. (1976). Discrimination and labeling of noise-buzz sequences with varying noise-lead times: An example of categorical perception. Journal of the Acoustical Society of America, 60, 410-417.

MILLER, J. L. (1977). Nonindependence of feature processing in initial consonants. Joumal of Speech \& Hearing Research, 20, 519-528.

MILLER, J. L. (1986). Rate-dependent processing in speech perception. In A. Ellis (Ed.), Progress in the psychology of language (Vol. III). Hillsdale, NJ: Eribaum.

PAstore, R. E. (1981). Possible psychoacoustic factors in speech perception. In P. D. Eimas \& J. L. Miller (Eds.), Perspectives in the study of speech (pp. 166-206). Hillsdale, NJ: Erlbaum. 
Pastore, R. E., Ahroon, W. A., Jr., Baffuto, K. A., Friedman. C. J.. Puleo, J. S., Fink, E. A. (1977). Common factor model of categorical perception. Journal of Experimental Psychology: Human Perception \& Performance, 3, 686-689.

Pastore, R. E., Harris, L. B., Kaplan, J. K. (1982). Temporal order identification: Some parameter dependencies. Joumal of the Acoustical Sociery of America, 71, 430-436.

Pastore, R. E., Morris, C. B., Logan, R. J., \& Layer, J. K. (1986). Duration effects revisited: Labeling of tone analogs to voicing contrasts. Joumal of the Acoustical Society of America, 79, S8. (Abstract)

Patterson, J. H., Green, D. M. (1970). Discrimination of transient signals having identical energy spectra. Journal of the Acoustical Society of America, 48, 894-905.

PIsONI, D. B. (1977). Identification and discrimination of the relative onset time of two-component tones: Implications for voicing perception in stops. Joumal of the Acoustical Society of America, 61, 1352-1361.

Pisoni, D., \& LAZArus, J. (1973). Categorical and noncategorical modes of speech perception along the voicing continuum. Journal of the Acoustical Society of America, 55, 328-333.

Pisoni, D., \& Lazarus, J. (1974). Auditory and phonetic memory codes in the discrimination of consonants and vowels. Perception \& Psychophysics, 13, 253-260.

REPP, B. H. (1979). Relative amplitude of aspiration noise as a voicing cue for syllable-initial stop consonants. Language \& Speech, 22 , 173-189.

Rosen, S., Howell, P. (1987). Is there a natural sensitivity at 20 $\mathrm{ms}$ in relative tone-onset-time continua? A reanalysis of Hirsh's (1959) data. In M. H. E. Schouten (Ed.), Psychophysics of speech perception (pp. 199-209). Boston: Nijhoff.

SAMUEL, G. (1977). The effect of discrimination training on speech perception: Noncategorical perception. Perception \& Psychophysics, 22, 321-330.

ShifFrin, R. M., \& SCHNeIder, W. (1977). Controlled and automatic human processing: II. Perceptual learning, automatic attending, and a general theory. Psychological Review, 84, 127-190.

Simon, C., * Fourcin, A. J. (1978). Cross-language study of speechpattern learning. Journal of the Acoustical Society of America, 63, 925-935.

Solt, S. (1983). The role of spectral cues in discrimination of voice onset time differences. Joumal of the Acoustical Society of America, 73, $2150-2165$.

Stevens, K. N., Klatt, D. H. (1974). Role of formant transitions in the voiced-voiceless distinction for stops. Journal of the Acoustical Society of America, 55, 653-659.

SUMmERFIELD, Q. (1981). On articulatory rate and perceptual constancy in phonetic perception. Journal of Experimental Psychology: Human Perception \& Performance, 7, 1074-1095.

Summerfield, Q. (1982). Differences between spectral dependencies in auditory and phonetic temporal processing: Relevance to the perception of voicing in initial stops. Journal of the Acoustical Society of America, 72, 51-61.

Summerfield, Q., HAGGard, M. P. (1977). On the dissociation of spectral and temporal cues to the voicing distinction in initial stop consonants. Journal of the Acoustical Society of America, 62, 435-448.

Treisman, A. M., \& Gelade, G. (1980). A feature-integration theory of attention. Cognitive Psychology, 12, 97-136.
Watson, C. S., Kel.t.y, W. J. (1981). The role of stimulus uncertainty in the discrimination of auditory parterns. In D. J. Getty \& J. H. Howard (Eds.), Auditory and viswal pattern recognition (pp. 37-59). Hillsdale, NJ: Erlbaum

Werker, J. F., Logan, J. S. (1985). Cross-language evidence for three factors in speech perception. Perception \& Psychophysics. 37, $35-44$

Wier, C. C., Green, D. M. (1975). Temporal acuity as a function of frequency difference. Joumal of the Acoustical Siciety of America. 52, $1512-1515$.

ZUE, V. W. (1976). Acoustic characteristics of stop consomants: A controlled study. Unpublished doctoral dissertation, M.I.T., Cambridge

\section{NOTES}

1. As in Pastore et al. (1982), we will use TOJ to refer to the temporal order judgment (or identification) threshold for the onset of stimulus components. The various stimulus onset-time continua will be referred to as voice onset time (VOT), tone onset time (TOT), and noise onset time (NOT). Also, using the convention suggested by Hillenbrand (1984). F $n$ will refer to vowel formant $n$, while $f \boldsymbol{n}$ will refer to the tone that is $n$th lowest in frequency and that is intended to be an analog to $F n$.

2. Hirsh (1959) found that the temporal order identification threshold was independent of most of the stimulus parameters he investigated. However, he did find that, for specific ranges of stimulus parameters, TOJ was (1) dependent on the duration, rise time, and relative intensity of the stimulus components, and (2) asymmetric for the onset of the two components.

3. Our summary does not include research with stimuli that are extremely brief (Patterson \& Green, 1970), where component differences are minimally detectable (Kelly \& Watson, 1986), or where the components are sequential (Wier \& Green, 1975), since these types of temporal resolution do not seem relevant to understanding the perception of voicing contrasts.

4. The subjects initially expressed confusion over the shift from the tone versus noise lead response required in Experiment 1 to the temporal 2IFC task in the subsequent experiments. In the 2IFC task, the subjects were instructed to use the two buttons (labeled 1 and 2) to indicate the stimulus with the longer onset difference. The subjects were not sure whether a first interval response indicated a "longer tone lead" (thus "shorter noise lead") than the second stimulus or a "longer noise lead" (thus a "shorter tone lead"). The subjects finally were instructed to make sure that they responded consistently within a given sequence, and the response decoding for each sequence was keyed on the comparison between the 0 -and 56-msec stimuli, with which the subjects either exhibited nearly $100 \%$ "correct" responding or, at best, responses that were marginally better than any of the other comparisons.

5 . If two means differ by $1.96 *$ (mean standand error) or $0.98 *$ (sum of standard errors), the difference is statistically significant with a probability of .05 for a two-tailed comparison. The criterion for a one-tailed comparison is $1.65 *$ (mean standard error) or $0.88 *$ (sum of standard errors). Since the direction of the differences is predicted, the one-tailed comparison is most appropriate.

(Manuscript received April 22, 1987; revision accepted for publication January 29,1988 . 